\title{
New frontiers in thermal plasma processing
}

\author{
Maher I. Boulos \\ Plasma Technology Research Centre (CRTP), Department of Chemical \\ Engineering, Université de Sherbrooke, Sherbrooke (Québec), Canada, J1K 2R1
}

\begin{abstract}
Thermal plasma technology applications are presently focused on two principal thrust areas: materials processing and the treatment of waste materials. Materials processing covers activities such as surface modification and plasma spray coating, powder spheroidization, and plasma chemical synthesis of ultrafine high purity materials. These have evolved as a mature science with considerable economic activity. Especially in the area of plasma spraying of protective coatings such as wear resistant and thermal barrier coatings. In the waste treatment area, the aim has been either the reclamation of waste material in order to recover higher added value products or the destruction of toxic wastes. A review is presented of the progress in each of these two frontiers. Research needs required to achieve significant advances in plasma source development, and fundamental understanding of the underlying fluid dynamics, heat and mass transfer phenomena, are discussed.
\end{abstract}

\section{INTRODUCTION}

The growing interest in thermal plasma technology has recently manifested itself by a large increase in the annual rate of US patents published in this area. Figure 1 presents a compilation of the number of US patents issued per year dealing with thermal plasma processing over the past thirty five years. The early rise of interest in the seventies, can be mostly associated with aerospace programs. Following a slowing of these activities in the early eighties, there seems to have been a major renewal of interest in thermal plasma technologies since 1984, with, for example, more than twenty such patents being published in the US in 1994. A general literature search reveals particular interest in the following two major thrust areas:

- Plasma materials processing.

- Plasma treatment of waste materials.

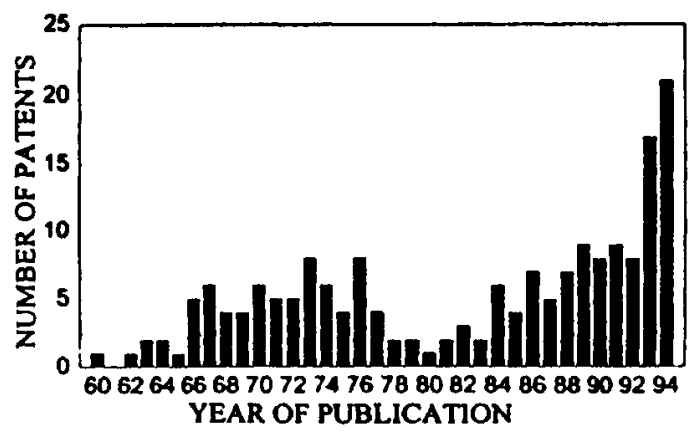

Figure 1. US patents published per year in the area of thermal plasma technology.

Recent developments and research needs in each of these two areas are discussed. Because of the close dependence of progress in such technologies on the availability of appropriate plasma generating devices, a brief discussion is presented on this topic.

\section{PLASMA GENERATION}

Three broad categories of plasma generating devices are used. These are; D.C. plasma torches, R.F. inductively coupled torches and microwave devices.

D.C. plasma torches are commonly available at power levels up to $1.5 \mathrm{MW}$. Scale up is possible to 6.0 MW. Two technologies are generally used. Hot cathode torches for power levels less than $200 \mathrm{~kW}$ while cold electrode torches are used at higher powers. A limited number of D.C. plasma generating devices are also available using graphite electrodes over both low and high power ranges. Transferred arcs at power levels up to 1.0 to $2.0 \mathrm{MW}$ are also used in a number of metallurgical and waste treatment processes. 
R.F. inductively coupled plasma torches are being increasingly considered for a wide range of applications in the areas of materials processing and the destruction of toxic wastes. These are commonly available for operation at power levels of $100 \mathrm{~kW}$. Scale up has been demonstrated to the $600 \mathrm{~kW}$ to 1.0 MW range. Two principal technologies are being considered for high power operation. These are the metal wall torches and the ceramic wall torch. A schematic representation of the ceramic wall torch, developed at our plasma technology research centre (CRTP) of the University of Sherbrooke [1-3], is shown in Figure 2. The main features of the design are an axial sheath gas flow to reduce the heat flux to the wall and the use of a high thermal conductivity, thermal shock resistant, ceramic tube for the plasma confinement, combined with high velocity water-film cooling. Operation of these torches has been demonstrated at power levels up to $120 \mathrm{~kW}$. Energy coupling efficiencies in the range of 65 to $75 \%$ have been measured using tube-type oscillators with overall torch efficiencies in the 40 to $50 \%$ range when using $\mathrm{Ar} / \mathrm{H}_{2}, \mathrm{O}_{2}$ or Air as the plasma sheath gas. Higher energy coupling efficiencies in the $90 \%$ range have recently been measured using all solid state power supplies, with corresponding overall torch efficiencies rising above $50 \%$.

\section{PLASMA MATERIALS PROCESSING}

Surface modification and coating using thermal plasma technology is by far the most important in terms of scientific maturity and economic activity. It covers such applications as the plasma spray coating of metals, ceramics and composites using atmospheric and low pressure plasmas, plasma diamond film deposition and other thin film coatings, using the PCVD and flash plasma vaporization techniques. Other examples of plasma surface treatment processes include transferred arc surface reclamation, and the surface treatment of granite rock.

Reviews on the subject have been published by Smith [4] and Boulos [5] covering the D.C. and R.F. induction plasma technologies respectively. As shown in Figure 3 the basic concept used involves the injection of material to be deposited in powder form into the discharge using a carrier gas stream. As the particles traverse the plasma, they are heated and melted and are then accelerated to velocities of hundreds of meters per second prior to impact on the substrate, where the molten droplets spread and rapidly solidify, forming a lamelar type deposit.

R.F. plasma deposition of refractory metals, plasma suspension deposition of hydroxyapatite and plasma reactive deposition, using the D.C. and R.F. plasma technologies, are some typical examples of relatively recent developments in this field.

Plasma chemical synthesis has been the subject of substantial investigation for more than four decades, with industrial scale applications maturing in the areas of acetylene production, $\mathrm{TiO}_{2}$ and high purity synthetic silica production, among others. Research efforts have also been maintained in the fields of ultrafine ceramic powder syntheses via the plasma route $\left(\mathrm{SiC}, \mathrm{Si}_{3} \mathrm{~N}_{4}, \mathrm{AlN}\right)$ and the synthesis of Fullerenes $\left(\mathrm{C}_{60}\right)$ which are still in various stages of development. The application outcome will mainly depend on the "yet to be demonstrated" technoeconomic considerations. 

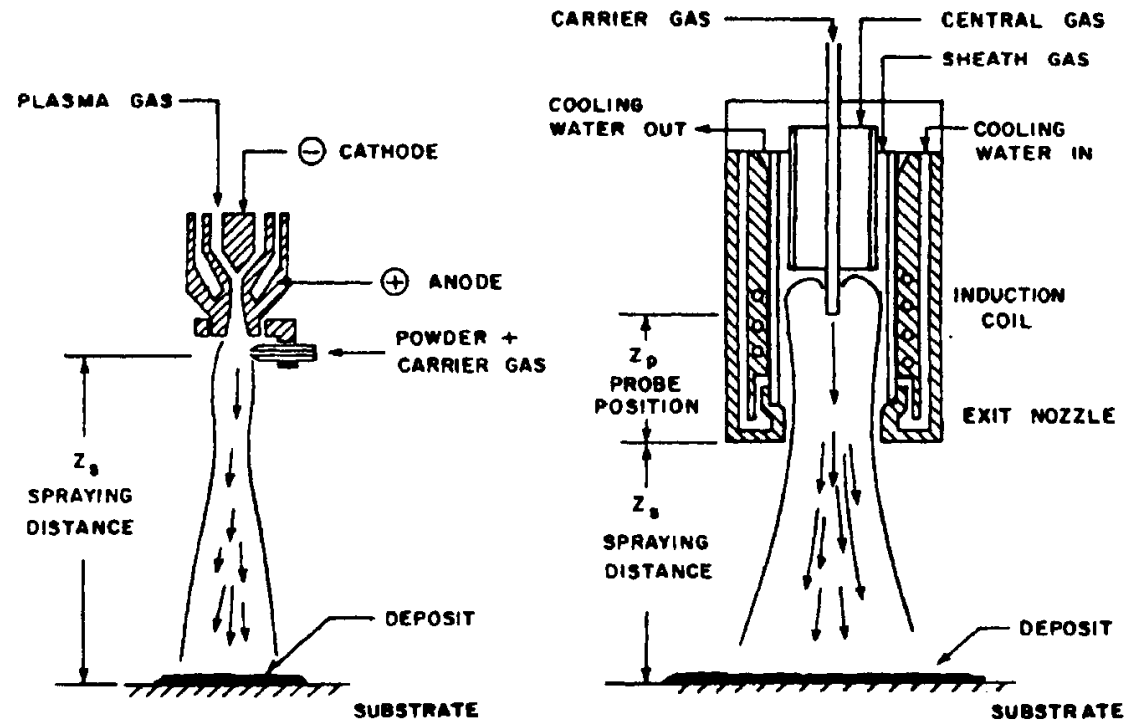

Figure 3. D.C. (left) and R.F. (right) plasma deposition of coatings and bulk material deposits.

\section{PLASMA TREATMENT OF WASTE MATERIALS}

Waste treatment is certainly one of the plasma application areas which bears promise and where plasma technology can have an important impact. Research activities in this area are aimed at either the reclamation of waste material in order to recover higher added value products or the rendering of waste to inert form or the destruction of toxic waste. In the first mentioned case, such as in aluminum dross processing, whether using the Alcan plasma technology or the Hydro-Québec LTEE carbon arc DROSCAR process, the objective is to recover the "free" aluminum metal present in the dross in a clean and efficient way, and in so doing eliminate the prospect of creating an environmental problem through the use of salt fluxes and other processing additives.

Other examples include baghouse dust smelting and scrap metal reclamation. Initial interest in the use of plasma technology for the destruction of toxic waste was mostly directed towards the PCB's problem. Result arising from development of this plasma technology could be equally successfully used for the destruction of a wide range of now unwanted and hazardous chemicals, ranging from Freons to toxic materials used by the military. Figure 4 shows a conceptual design of an induction plasma waste treatment process in which the waste material is either axially injected into the center of the discharge, or radially injected into the plasma jet. Destruction efficiencies as high as $99.999 \%$ of CFC were obtained using a steam plasma [6].

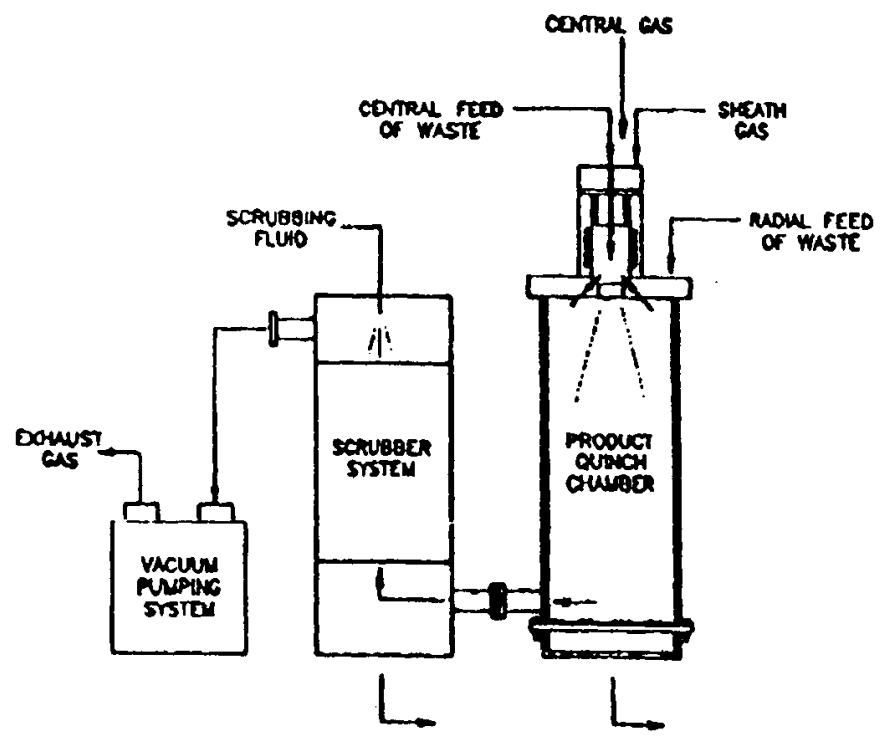

Figure 4.

Conceptual design of an induction plasma waste treatment process. 


\section{RESEARCH NEEDS}

Progress with each of the above identified thrust areas of plasma materials processing and waste treatment will depend to a large extent on our understanding of the basic phenomena involved. While we have made important progress in the area of thermal plasma source development, whether in D.C. or R.F. induction generated plasmas, plasma and particle diagnostics and mathematical modeling, particular attention continues to be needed in the following areas:

Study of the fluid dynamics, heat and mass transfer phenomena under plasma conditions. Far more work still needs to be done in dealing with the study of the mass transfer phenomena involved in such relatively complex laminar and turbulent flow process conditions.

- Plasma-substrate and particle-substrate interactions occurring during the plasma spray coating processes. Early results indicate that these interactions strongly depend on the substrate temperature which in turn will have an important influence on residual stress distributions and other mechanical effects in the deposits.

High temperature chemical kinetics. A serious lack of data presently exists for the wide range of possible chemical reactions that are potentially involved in most of the waste treatment applications of plasma processing. This data is not only needed to insure complete destruction of the treated waste material, but also in avoiding the formation of undesirable side reaction product.

Programs on each of these three critical areas, coupled with systematic progress in diagnostic and mathematical modeling techniques, will have a major influence on our ability to broaden the present applications of plasma technology to new areas and will certainly facilitate the necessary scale up steps required to take a promising process from the laboratory stage to full scale industrial operation. This work is also much needed for progress with process optimization on solid scientific grounds.

\section{REFERENCES}

1. M.I. Boulos, "Radio frequency plasma developments; scale up and industrial application", J. High Temperature Chemical Processes, 1, 401-411 (1992).

2 J. Jurewicz and M. I. Boulos, "High energy density induction plasma system for materials processing", Proceedings NTSC-93, pp. 89-95, Anaheim, CA, 7-11 June (1993).

3. M.I. Boulos and J. Jurewicz, "High performance induction plasma torch with a water-cooled ceramic confinment tube" US patent 5200595 April 6 (1993), International patent application PCT/CA92/00156.

4. 5R.H. Smith and R.Novak, "Advances and applications in U.S.Thermal Spray Technology," Powder Metallurgy International, 23, 147 (1991).

5. M. Boulos, R.F. induction plasma spraying, state-of-the-art review", J. of Thermal Spray Technology, 1, 33-40 (1992).

6. K. Mizuno et al, U.S. Patent 5187 344, Feb. 16 (1993). 